\title{
Pengaruh Kemampuan Manajemen Terhadap Kinerja Industri Kecil Menengah (IKM) Sasirangan di Provinsi Kalimantan Selatan
}

\author{
Maskur \\ maskur.56@gmail.com \\ Universitas Islam Kalimantan (UNISKA) MAB Banjarmasin
}

\begin{abstract}
Krisis ekonomi yang terjadi di negara Indonesia sejak beberapa waktu yang lalu, dimana banyak usaha berskala besar yang mengalami stagnasi bahkan berhenti aktifitasnya. Sektor Industri Kecil Menengah $\{\mathrm{IKM}\}$ terbukti lebih tangguh dalam menghadapi krisis tersebut. Mengingat pengalaman yang telah dihadapi oleh Indonesia selama krisis, kiranya tidak berlebihan apabila pengembangan sektor swasta difokuskan pada IKM. Penempatan IKM pada posisi sangat strategis tersebut karena IKM dianggap dapat memenuhi kebutuhan untuk mendiversifikasi perekonomian nasional agar dapat melindunginya terhadap fluktuasi dan kresisi ekonomi. Kemampuan manajemen sangatlah penting dalam industri kecil, menengah dan industri besar, dimana masing-masing memerlukan kegiatan manajemen untuk melakukan koordinasi dalam kemampuan atau skill yang dimiliki pekerja maupun koodinasi sumber-sumber yang dimiliki oleh perusahaan. Tujuan dari penelitian ini adalah menguji dan menjelaskan pengaruh kemampuan manajemen terhadap kinerja Industri Kecil Menengah (IKM) Sasirangan di Provinsi Kalimantan Selatan. Metode yang digunakan adalah pendekatan kuantitatif (positivism), karena data yang diperoleh dari hasil survey dalam bentuk angka atau bilangan yang selanjutnya dianalisis menggunakan statistik untuk menjawab pertanyaan dan menguji hipotesis penelitian. Hasil penelitian menunjukkan bahwa kemampuan manajemen berpengaruh signifikan secara langsung yang bersifat positif terhadap Kinerja IKM. Hasil GeSCA diperoleh koefisien jalur sebesar $0,029^{*}$ dan $C R=4.28^{*}$ (signifikan) bertanda positif.. Hasil ini menunjukkan bahwa kemampuan manajemen yang dimiliki oleh pemilik IKM sasirangan dapat meningkatkan kinerja IKM.
\end{abstract}

Keyword: Industri Kecil Menegah (IKM), manajemen 


\section{PENDAHULUAN}

Industri Kecil Menengah itu sendiri

Perkembangan IKM di Indonesia terus mengalami peningkatan yang sangat berarti, termasuk pelaku IKM di provinsi Kalimantan Selatan khususnya industri sasirangan. Pertumbuhan IKM sasirangan di Kalimantan Selatan menunjukkan trend yang positif, ini seiring dengan semakin meningkatnya jumlah IKM sasirangan sejak sasirangan diakui sebagai warisan budaya Kalimantan Selatan oleh departemen perindustrian pusat tahun 1986 melalui proyek P2W-IK (Peningkatan Peranan Wanita Industri Kecil) UNDP. Keberadaan IKM sasirangan saat ini terus mendapat perhatian serius dari pemerintah daerah sebagai keunggulan bersaing yang dimiliki Provinsi Kalimantan Selatan, disisi lain sasirangan juga telah memberikan andil yang bersifat multiplier effect baik terhadap maupun pada level perusahaan.

Banyak hal yang yang dapat mempengaruhi besar kecilnya nilai produksi suatu usaha, di antaranya adalah kemampuan manajemen dalam mengikuti perubahan lingkungan. Industri Kecil Menengah sasirangan di Kalimantan Selatan mempunyai permasalahan yang sama dengan permasalahan yang umum yang dihadapi oleh IKM yang ada di Indonesia, antara lain menyangkut desain produk yang monoton atau kurang kreatif, demikian juga dalam hal bahan baku dan pewarna masih belum banyak variasinya.

Pertumbuhan

IKM memerlukan kinerja yang baik dari pengusahanya sehingga mampu membuat industri ini menjadi dinamis dalam menghadapi lingkungan usahanya. Stainhoff dan Burgess (1993) menjelaskan bahwa beberapa karakteristik yang 
diperlukan untuk menjadi kinerja usaha kecil dan manufaktur. wirausaha yang berhasil yaitu: Namun tidak demikian Ursic dan memiliki visi dan tujuan usaha yang Mulej (2005) menyatakan pendapat jelas, bersedia menanggung risiko waktu dan uang, bekerja dengan perencanaan dan pengorganisasian, kerja keras sesuai dengan tingkat urgensinya, mengembangkan yang berbeda bahwa kemampuan manajemen secara langsung berpengaruh tidak signifikan terhadap kinerja usaha.

METODE PENELITIAN

hubungan dengan pelanggan,

Pendekatan yang pemasok, pekerja dan sebagainya, bertanggung jawab terhadap keberhasilan dan kegagalan. digunakan dalam peneltian ini adalah pendekatan kuantitatif (positivism), karena data yang

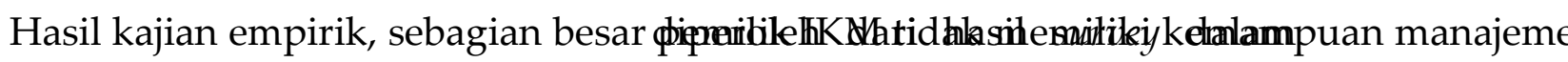
diri sendiri maupun warisan dari bentuk angka atau bilangan yang orang tua. Beberapa hasil kajian selanjutnya dianalisis menggunakan empirik menemukan bahwa statistik untuk menjawab kemampuan manajemen pertanyaan dan menguji hipotesis berpengaruh signifikan terhadap kinerja bisnis pada industri kecil dan manufaktur (Chi et al,. 2011; Wai dan Kuan, 2011; Dani et al., 2013; Fening, 2012). Hal tersebut dipertegas oleh Chi et al. (2011) yang menjelaskan bahwa kemampuan manajemen jika didukung dengan berbagai pengetahuan yang baik maka akan dapat meningkatkan penelitian. Hasil uji statistik tersebut digunakan untuk menjelaskan kedudukan variabel-variabel yang diteliti, serta memprediksi keterkaitan variabel satu dengan variabel lainnya (Creswell, 2009).

Populasi dalam penelitian ini sebanyak 86 pemilik Industri Kecil Menengah Sasirangan yang ada di tiga Kota/Kabupaten Provinsi 
Kalimantan Selatan, dan juga sebagai sampel dalam penelitian ini (sensus). Menurut Undang-undang No. 20 Tahun 2008.

Tabel 1. Populasi dan Sampel IKM Sasirangan

\begin{tabular}{|c|c|c|c|}
\hline $\mathbf{N}$ & $\begin{array}{c}\text { Kota/Kabupa } \\
\text { ten }\end{array}$ & $\begin{array}{c}\text { Popula } \\
\text { si }\end{array}$ & $\begin{array}{c}\text { Samp } \\
\text { el }\end{array}$ \\
\hline 1 & Banjarmasin & 48 & 48 \\
\hline 2 & Martapura & 29 & 29 \\
\hline 3 & Banjarbaru & 9 & 9 \\
\hline & Jumlah & 86 & 86 \\
\hline
\end{tabular}

Sumber: Disperindag Prov. Kalsel, 2016

Tabel 2. Rekapitulasi Distribusi, Pengembalian dan Penggunaan Kuesioner Penelitian

\begin{tabular}{|l|c|c|}
\hline \multicolumn{1}{|c|}{ Keterangan } & $\begin{array}{c}\text { Frekuens } \\
\text { i }\end{array}$ & $\begin{array}{c}\text { Persentas } \\
\text { e (\%) }\end{array}$ \\
\hline $\begin{array}{l}\text { Kuesioner } \\
\text { penelitian } \\
\text { yang } \\
\text { didistribusika } \\
\text { n }\end{array}$ & 86 & 100 \\
\hline $\begin{array}{l}\text { Kuesioner } \\
\text { penelitian } \\
\text { yang kembali }\end{array}$ & 86 & 100 \\
\hline $\begin{array}{l}\text { Kuesioner } \\
\text { penelitian } \\
\text { yang tidak } \\
\text { lengkap }\end{array}$ & 3 & 3.49 \\
\hline $\begin{array}{l}\text { Kuesioner } \\
\text { penelitian } \\
\text { yang } \\
\text { digunakan }\end{array}$ & 83 & 96.51 \\
\hline
\end{tabular}

Sumber: Data dioleh, 2016
Variabel

dalam

penelitian ini adalah Kemampuan manajemen (management skills) dari para wirausaha (entrepreneur) merupakan sekumpulan keahlian dan kompetensi baik secara administratif maupun operatif dalam menjalankan fungsi-fungsi manajemen yang terdiri dari kemampuan untuk membuat perencanaan, mengorganisasi, mengarahkan, atau melakukan penugasan dan melakukan pengawasan. Selanjutnya indikator dari variabel kemampuan manajemen meliputi :

a. Perencanaan adalah pemilihan dan penetapan tujuan-tujuan organisasi dan penentuan strategi, kebijaksanaan, program, prosedur, metode, sistem, anggaran dan standar yang dibutuhkan untuk mencapai tujuan-tujuan organisasi

b. Pengorganisasian adalah penentuan sumberdaya- 
sumberdaya dan kegiatankegiatan yang dibutuhkan untuk mencapai tujuan organisasi. perancangan dan pengembangan suatu organisasi atau kelompok kerja yang akan membawa hal tersebut ke arah tujuan

c. Mengarahkan atau melakukan penugasan penyusunan personalia (staffing) adalah penarikan (recruitment), pelatihan dan pengembangan serta penempatan pemberian orientasi para karyawan dalam lingkungan kerja yang menguntungkan dan produktif

d. Pengawasan adalah pengukuran atau perbaikan terhadap pelaksanaan kerja bawahan agar rencana-rencana yang telah dibuat untuk mencapai tujuan organisasi dapat terselenggara dengan baik.

\section{HASIL DAN PEMBAHASAN}

\section{Deskripsi Variabel Kemampuan}

\section{Manajemen (X)}

Variabel

Kemampuan

Manajemen $(X)$ diukur dengan empat Indikator, yaitu: Indikator Perencanaan $\quad(\mathrm{X} .1), \quad$ Indikator Pengorganisasian $\left(\mathrm{X}_{2}\right)$, Indikator Pengarahan $\left(X_{.3}\right)$ dan Indikator Pengawasan $\quad\left(\mathrm{X}_{2.4)}\right) \quad$ Indikator Perencanaan $\left(X_{.1}\right)$ terdiri dari dua item, Indikator Pengorganisasian $\left(\mathrm{X}_{2}\right)$, dua item, Indikator Pengarahan (X.3) dua item dan Indikator Pengawasan (X.4). dua item. Distribusi frekuensi variabel Kemampuan Manajemen (X) dapat dilihat pada Tabel 3

Tabel 3 Deskripsi Indikator/item dari Variabel Kemampuan Manajemen (X)

\begin{tabular}{|c|c|c|c|c|c|c|c|c|c|c|c|c|}
\hline \multirow{3}{*}{$\begin{array}{c}\text { Indikat } \\
\text { or }\end{array}$} & \multirow{3}{*}{ Item } & \multicolumn{10}{|c|}{ Skor Jawaban Responden } & \multirow{3}{*}{ Mean } \\
\hline & & \multicolumn{2}{|c|}{1} & \multicolumn{2}{|c|}{2} & \multicolumn{2}{|c|}{3} & \multicolumn{2}{|c|}{4} & \multicolumn{2}{|c|}{5} & \\
\hline & & $\mathrm{f}$ & $\%$ & $\mathrm{f}$ & $\%$ & $\mathrm{f}$ & $\%$ & $\mathrm{f}$ & $\%$ & $\mathrm{f}$ & $\%$ & \\
\hline \multirow{2}{*}{$(\mathrm{X} 1)$} & $\mathrm{X}_{1.1}$ & 0 & 0 & 0 & 0 & 2 & 2,4 & 46 & $\begin{array}{c}55, \\
4\end{array}$ & 3 & $\begin{array}{l}42, \\
2\end{array}$ & 4,40 \\
\hline & $X_{1.2}$ & 0 & 0 & 0 & 0 & 3 & 3,6 & 51 & $\begin{array}{c}61, \\
4\end{array}$ & $\begin{array}{l}2 \\
9\end{array}$ & $\begin{array}{l}34, \\
9\end{array}$ & 4,31 \\
\hline
\end{tabular}




\begin{tabular}{|c|c|c|c|c|c|c|c|c|c|c|c|c|}
\hline & \multicolumn{11}{|c|}{ Mean Indikator Perencanaan } & 4,36 \\
\hline \multirow{3}{*}{$(\mathrm{X} 2)$} & $X_{2.1}$ & 1 & 1,2 & 6 & 7,2 & 3 & 3,6 & 47 & $\begin{array}{c}56 \\
6\end{array}$ & $\begin{array}{l}2 \\
6\end{array}$ & $\begin{array}{l}31, \\
3\end{array}$ & 4,10 \\
\hline & $\mathrm{X}_{2.2}$ & 0 & 0 & 1 & 1,2 & 8 & 9,6 & 44 & 53 & $\begin{array}{l}3 \\
0\end{array}$ & $\begin{array}{l}36, \\
1\end{array}$ & 4,24 \\
\hline & \multicolumn{11}{|c|}{ Mean Indikator Pengorganisasian } & 4,17 \\
\hline \multirow[t]{3}{*}{$(\mathrm{X} 3)$} & $\mathrm{X}_{3.1}$ & 0 & 0 & 0 & 0 & 1 & 1,2 & 40 & $\begin{array}{c}48 \\
2 \\
\end{array}$ & $\begin{array}{l}4 \\
2\end{array}$ & $\begin{array}{l}50, \\
6\end{array}$ & 4,49 \\
\hline & $X_{3.2}$ & 0 & 0 & 0 & 0 & $\begin{array}{l}1 \\
1 \\
\end{array}$ & $\begin{array}{c}13 \\
3 \\
\end{array}$ & 29 & $\begin{array}{c}34 \\
9 \\
\end{array}$ & $\begin{array}{l}4 \\
3 \\
\end{array}$ & $\begin{array}{l}51, \\
8\end{array}$ & 4,39 \\
\hline & \multicolumn{11}{|c|}{ Mean Indikator Pengarahan } & 4,44 \\
\hline \multirow[t]{4}{*}{$(\mathrm{X} 4)$} & $\mathrm{X}_{4.1}$ & 0 & 0 & 0 & 0 & 0 & 0 & 32 & $\begin{array}{c}38 \\
6\end{array}$ & $\begin{array}{l}5 \\
1\end{array}$ & $\begin{array}{c}61 \\
4\end{array}$ & 4,61 \\
\hline & $X_{4.2}$ & 1 & 1,2 & 0 & 0 & 7 & 8,4 & 35 & $\begin{array}{c}42 \\
2\end{array}$ & $\begin{array}{l}4 \\
0\end{array}$ & $\begin{array}{c}48 \\
2\end{array}$ & 4,36 \\
\hline & \multicolumn{11}{|c|}{ Mean Indikator Pengawasan } & 4,49 \\
\hline & \multicolumn{11}{|c|}{ Mean Variabel Kemampuan Manajemen } & 4,36 \\
\hline
\end{tabular}

Sumber : Data diolah

Keterangan : X1 : Indikator Perencanaan

X2 : Indikator Pengorganisasian

X3 : Indikator Pengarahan

X4 : Indikator Pengawasan

2. Deskripsi Variabel Kinerja IKM (Y)

\section{Variabel Kinerja IKM}

(Y) diukur dengan tiga Indikator, yaitu Pertumbuhan Penjualan (Y1). Pertumbuhan Keuntungan (Y2). Pertumbuhan Modal (Y3). Indikator pertumbuhan penjualan (Y1) terdiri Tabel 4. Distribusi Indikator/Item dari Variabel Kinerja IKM (Y)

\begin{tabular}{|c|c|c|c|c|c|c|c|c|c|c|c|c|}
\hline \multirow{3}{*}{$\begin{array}{c}\text { Indika } \\
\text { tor }\end{array}$} & \multirow{3}{*}{$\begin{array}{c}\text { Ite } \\
\text { m }\end{array}$} & \multicolumn{10}{|c|}{ Skor Jawaban Responden } & \multirow{3}{*}{ Mean } \\
\hline & & \multicolumn{2}{|c|}{1} & \multicolumn{2}{|c|}{2} & \multicolumn{2}{|c|}{3} & \multicolumn{2}{|c|}{4} & \multicolumn{2}{|c|}{5} & \\
\hline & & $\mathrm{f}$ & $\%$ & $\mathbf{f}$ & $\%$ & $\mathbf{f}$ & $\%$ & $\mathbf{F}$ & $\%$ & f & $\%$ & \\
\hline \multirow[t]{2}{*}{$(\mathrm{Y} 1)$} & $\mathrm{Y}_{1.1}$ & 0 & 0 & 0 & 0 & 2 & 2,4 & 38 & 45,8 & $\begin{array}{l}4 \\
3 \\
\end{array}$ & 51,8 & 4,49 \\
\hline & $Y_{1.2}$ & 0 & 0 & 0 & 0 & 4 & 4,8 & 36 & 43,4 & 4 & 51,8 & 4,47 \\
\hline
\end{tabular}

atas 2 (dua) item, Indikator pertumbuhan keuntungan (Y2) terdiri atas 2 (dua) item dan Indikator pertumbuhan modal (Y3) terdiri atas 2 (dua) item. Distribusi frekuensi variabel Kinerja IKM (Y) dapat di lihat pada Tabel 4. 


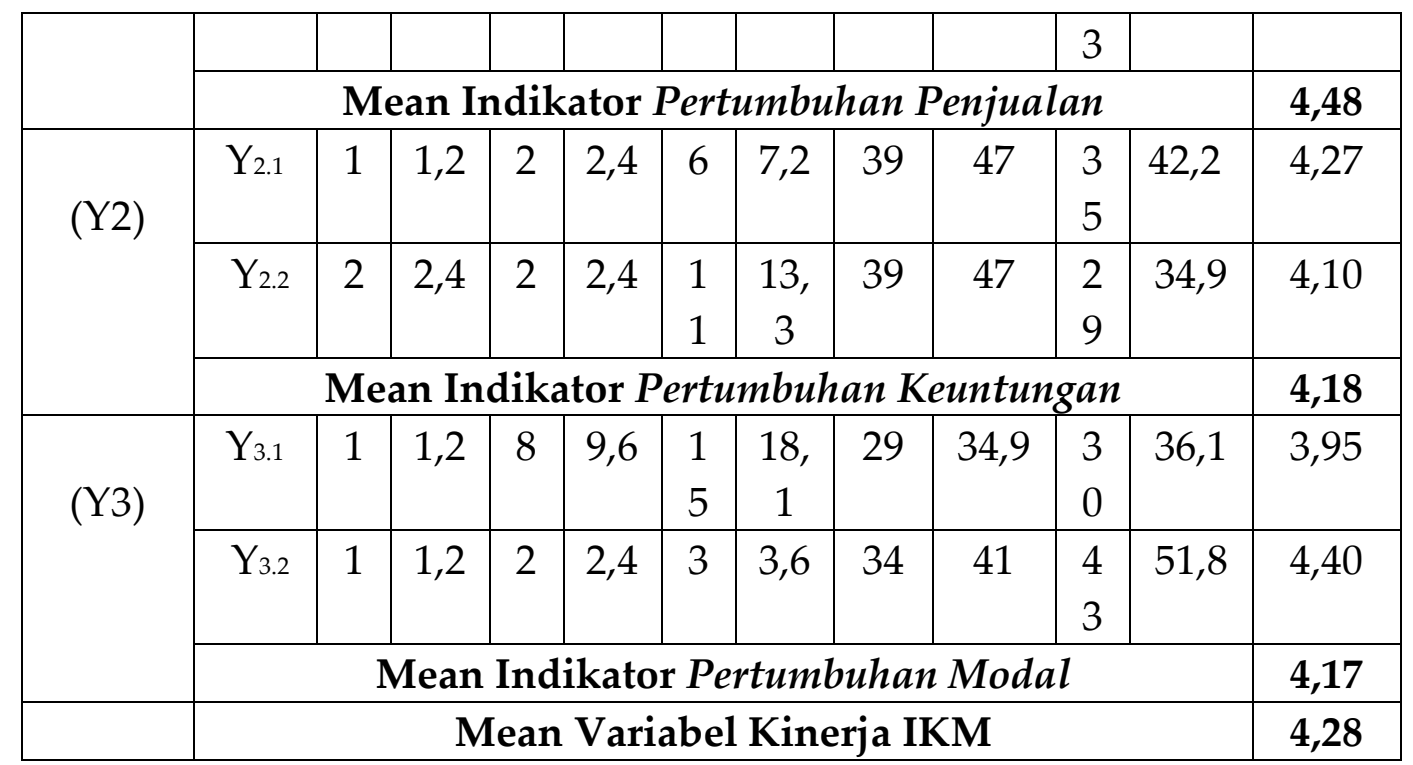

Sumber : Data diolah

Keterangan: Y1.1 Indikator Pertumbumbuhan Penjualan

Y1.2 Indikator Pertumbuhan Keuntungan

Y1.3 Indikator Pertumbuhan Modal

\section{Pembahasan Deskripsi Variabel}

\section{Kemampuan Manajemen (X)}

Kemampuan manajemen

merupakan sekumpulan keahlian

dan kompetensi baik secara

administratif maupun operasional

dalam menjalankan fungsi-fungsi

manajemen dalam organisasi untuk

mencapai tujuan tertentu. Indikator

yang digunakan untuk mengukur

variabel Kemampuan Manajemen

(X) diukur dengan 4 indikator yaitu:

Indikator Perencanaan $\left(X_{1}\right)$,

Indikator Pengorganisasian $\left(X_{2}\right)$,

Indikator Pengarahan $\left(X_{3}\right)$ dan
Indikator Pengawasan $\left(X_{4}\right)$. Setiap indikator kemudian dikembangkan menjadi beberapa item sebagai pengukur.

Indikator perencanaan diukur dengan 2 (dua) item, yaitu memiliki kemampuan untuk membuat perencanaan strategi $\left(X_{1.1}\right)$, membuat keputusan sendiri dengan baik tampa bantuan orang lain $\left(\mathrm{X}_{1.2}\right)$. Hasil Measurement model untuk indikator ini menunjukkan kedua item valid dan signifikan pada $\alpha=$ 0,05 terhadap perencanaan. Kedua item tersebut merupakan faktor 
yang dinilai dominan dalam mencerminkan perencanaan karena loading-nya tidak berbeda. Nilai loading kedua item tersebut, sebesar 0.876 dan 0.848 .

Indikator kedua sebagai pengukur konstruk Kemampuan Manajemen (X) adalah indikator pengorganisasian yang diukur dengan menggunakan 2 (dua) item. Kedua item tersebut yaitu mendistribusikan pekerjaan dengan baik kepada karyawan (X.2.1), membangun team kerja yang handal $\left(\mathrm{X}_{2.2 .2}\right)$. Hasil Measurement model untuk indikator ini menunjukkan kedua item valid dan signifikan pada $\alpha=0,05$ terhadap perencanaan.

Kedua item tersebut merupakan faktor yang dinilai dominan dalam mencerminkan perencanaan karena loading-nya tidak berbeda. Nilai estimat kedua item tersebut, sebesar 0.858 dan 0.865 .

Indikator ketiga sebagai pengukur konstruk Kemampuan Manajemen (X) adalah indikator pengarahan yang diukur dengan menggunakan 2 (dua) item. Kedua item tersebut yaitu berkomunikasi dengan baik terhadap karyawan (X.3.1), menyelesaikan pekerjaan tepat waktu (X.3.2). Hasil Measurement model untuk indikator ini menunjukkan kedua item valid dan signifikan pada $\alpha=0,05$ terhadap pengarahan. Item menyelesaikan pekerjaan tepat waktu (X.3.2). merupakan faktor tertinggi yang dinilai dalam mencerminkan indikator pengarahan karena memiliki loading yang terbesar, Nilai loading item tersebut sebesar 0.908. Untuk item berkomunikasi dengan baik terhadap karyawan $\left(\mathrm{X}_{3.1}\right)$, memberikan kontribusi terhadap indikator ipengarahan dengan nilai loading sebesar 0.875 . Indikator keempat sebagai pengukur konstruk Kemampuan Manajemen (X) adalah indikator pengawasan yang diukur dengan menggunakan 2 (dua) item. Kedua item tersebut yaitu 
melakukan perubahan kearah pekerjaan demi tercapainya tujuan perusahaan yang lebih baik $\left(X_{4.1}\right)$, mampu menyelesaikan konflik yang terjadi antara perusahaan dengan karyawan maupun dengan pelanggan $\left(\mathrm{X}_{4.2}\right)$. Hasil Measurement model untuk indikator ini menunjukkan kedua item valid dan signifikan pada $\alpha=0,05$ terhadap pengawasan. Kedua item tersebut merupakan faktor yang dinilai dominan dalam mencerminkan perencanaan karena loading-nya tidak berbeda. Nilai loading kedua item tersebut, sebesar 0.886 dan 0.878 .

Keempat (4) indikator pembentuk konstruk Kemampuan Manajemen $(X)$ adalah valid, dan berdasarkan hasil loading maka dapat dideskripsikan bahwa untuk indikator pengarahan, item yang paling berkontribusi adalah (X3.2) yaitu menyelesaikan pekerjaan tepat waktu dengan nilai sebesar 0.908 . Untuk indikator pengawasan, item yang paling berkontribusi adalah (X4.1) yaitu melakukan perubahan kearah pekerjaan demi tercapainya tujuan perusahaan yang lebih baik dengan nilai sebesar sebesar 0.886 . Untuk indikator perencanaan, item yang paling berkontribusi adalah $\left(X_{1.1}\right)$ yaitu memiliki kemampuan untuk membuat perencanaan strategi dengan nilai sebesar sebesar 0.876. Untuk indikator pengorganisasian, item yang paling berkontribusi adalah $\left(\mathrm{X}_{2.2}\right)$. yaitu membangun team kerja yang handal dengan nilai sebesar 0.865 . Keempat indikator pembentuk konstruk Kemampuan Manajemen (X) yang paling besar kontribusinya adalah indikator pengarahan dan yang paling lemah adalah pengorganisasian.

\section{Pembahasan Deskripsi Variabel}

Kinerja IKM (Y)

Kinerja IKM dalam penelitian ini dimaknai sebagai tingkat pencapaian atau prestasi dari perusahaan dalam periode waktu 
tertentu dan kinerja sebuah perusahaan adalah hal yang sangat menentukan dalam perkembangan perusahaan. Indikator yang digunakan untuk mengukur variabel Kinerja IKM (Y) yaitu: Indikator Pertumbuhan Penjualan (Y1). Pertumbuhan Keuntungan (Y2). Pertumbuhan Modal (Y3). Setiap indikator kemudian dikembangkan menjadi beberapa item sebagai pengukur.

Indikator Pertumbuhan Penjualan diukur dengan 2 (dua) item, yaitu peningkatan penjualan (omzet) IKM dari tahun ke tahun (Y1.1), peningkatan penjualan (omzet) juga diikuti dengan peningkatan produksi (Y1.2). Hasil Measurement model untuk indikator ini menunjukkan seluruh item valid dan signifikan pada $\alpha=$ 0,05 terhadap pertumbuhan penjualan. Item peningkatan penjualan (omzet) juga diikuti dengan peningkatan produksi (Y1.2) dan penjualan (omzet) meningkat dari tahun ke tahun (Y1.1), merupakan dua faktor yang dinilai dominan dalam mencerminkan pertumbuhan penjualan mengingat besarnya loading yang tidak berbeda signifikan, Nilai estimate item tersebut yaitu 0.928 dan 0.917 .

Indikator kedua sebagai pengukur konstruk Kinerja IKM (Y) adalah Pertumbuhan Keuntungan (Y2) yang diukur dengan menggunakan 2 (dua) item, yaitu: laba meningkat dari tahun ke tahun (Y2.1), peningkatan laba yang diperoleh lebih tinggi dari peningkatan modal yang digunakan (Y2.2). Hasil Measurement model diperoleh untuk indikator ini menunjukkan seluruh item valid dan signifikan pada $\alpha=0,05$ terhadap Kinerja IKM. Item peningkatan laba yang diperoleh lebih tinggi dari peningkatan modal yang digunakan (Y2.2). merupakan faktor tertinggi yang dinilai dalam mencerminkan indikator 
pertumbuhan keuntungan karena memiliki loading yang terbesar, nilai loading item tersebut sebesar 0.914. Besar kontribusi item lainnya adalah (Y2.1), laba meningkat dari tahun ke tahun. Nilai loading item tersebut sebesar 0.862 .

Indikator ketiga sebagai pengukur konstruk Kinerja IKM (Y) adalah pertumbuhan modal (Y3), yang diukur dengan menggunakan 2 (dua) item. Kedua item tersebut adalah jumlah modal dari tahun ke tahun meningkat (Y3.1), tambahan modal diperlukan untuk perkembangan usaha menjadi lebih besar lagi (Y3.2). Hasil Measurement model diperoleh untuk indikator ini menunjukkan seluruh item valid dan signifikan pada $\alpha=0,05$ terhadap strategi fokus. Item jumlah modal dari tahun ke tahun meningkat (Y3.1) dan tambahan modal diperlukan untuk perkembangan usaha menjadi lebih besar lagi (Y3.2) merupakan dua faktor yang dinilai dominan dalam mencerminkan pertumbuhan modal mengingat besarnya loading yang tidak berbeda signifikan, Nilai loading item tersebut yaitu 0.854 dan 0.859 .

Ketiga (3) indikator pembentuk konstruk Kinerja IKM (Y) adalah valid dan berdasarkan hasil loading maka dapat dideskripsikan bahwa untuk indikator pertumbuhan penjualan, item yang paling berkontribusi adalah (Y2.1) yaitu peningkatan penjualan (omzet) IKM dari tahun ke tahun dan (Y2.2), peningkatan penjualan (omzet) juga diikuti dengan peningkatan produksi, mengingat besarnya loading yang tidak berbeda signifikan dengan nilai 0.865 dan 0.865. Untuk indikator pertumbuhan keuntungan, item yang paling berkontribusi adalah (Y2.2). yaitu peningkatan laba yang diperoleh lebih tinggi dari peningkatan modal yang digunakan dengan nilai sebesar 0.914. Untuk indikator 
pertumbuhan modal, item yang paling berkontribusi adalah (Y3.2) yaitu tambahan modal diperlukan untuk perkembangan usaha menjadi lebih besar lagi dengan nilai sebesar 0.859 . Ketiga indikator pembentuk Kinerja IKM (Y) yang paling besar kontribusinya adalah indikator pertumbuhan keuntungan dan yang paling rendah adalah indikator pertumbuhan modal.

\section{Pengaruh Kemampuan} Manajemen terhadap Kinerja IKM

Kemampuan Manajemen berpengaruh signifikan bersifat positif terhadap Kinerja IKM. Hasil GeSCA diperoleh koefisien jalur sebesar $0,029^{*}$ dan $\mathrm{CR}=4.28^{*}$ (signifikan) bertanda positif. Hasil ini menunjukkan bahwa kemampuan manajemen yang dimiliki oleh pemilik IKM sasirangan secara langsung dapat meningkatkan kinerja IKM. Temuan ini memberi petunjuk bahwa pelaksanaan kemampuan manajemen yang meliputi perencanaan, pengorganisasian, pengarahan, dan pengawasan sebagai pembentuk variable kemampuan manajemen dapat digunakan secara langsung untuk meningkatkan pertumbuhan penjualan, pertumbuhan keuntungan dan pertumbuhan modal sebagai pembentuk variable kinerja IKM. Pembentuk variabel kemampuan manajemen yang paling dominan adalah indikator pengarahan yaitu menyelesaikan pekerjaan tepat waktu. Kemudaian pembentuk variabel Kinerja IKM yang paling besar kontribusinya adalah indikator pertumbuhan penjualan, melalui item penjualan (omzet) meningkat dari tahun ke tahun.

Temuan yang dihasilkan dalan penelitian ini mendukung hasil penelitian terdahulu yang dilakukan oleh Akgun et al. (2008), dengan mengambil sampel sejumlah 356 responden dari 112 
perusahaan, melibatkan manajer dan karyawan dari berbagai perusahaan yang beroperasi di Istambul. Analisis data yang digunakan adalah analisis regresi hirarkis, dengan hasil penelitian menunjukkan kemampuan emosional perusahaan berpengaruh signifikan dan positif terhadap kinerja keuangan perusahaan dan efetivitivitas organisasi. Selanjutnya hasil temuan Man dan Wafa (2008) dengan mengambil sampel 100 UKM di sektor manufaktur di Malaysia, menggunakan kuesioner terstruktur dan wawancara dengan pemilik-pengelola UKM. Analisis data menggunakan regresi berganda dan analisis One-Way ANOVA, dengan hasil penelitian menunjukkan kemampuan manajemen berpengaruh positif dan signifikan terhadap kinerja usaha kecil menengah (UKM). Temuan penelitian ini juga sejalan dengan penelitian Suci (2009) dengan hasil kesimpulan menujukkan bahwa kemampuan

manajemen

berpengaruh positif signifikan terhadap kinerja, dengan kata lain bahwa kemampuan manajemen yang cukup dapat menentukan keberhasilan kinerja IKM. Hasil temuan ini juga didukung beberapa penelitian lainnya seperti Wai dan Kuan (2011), Chi et al (2011), Hsu (2012), Fening (2012), dan Dani et al. (2013) yang menyimpulkan bahwa kemampuan manjemen berpengaruh langsung terhadap kinerja. Hasil penelitian ini berbeda dengan penelitian sebelumnya yang terkait dengan kemampuan manajemen dan kinerja IKM oleh Ursic dan Mulej (2005) menyatakan pendapat bahwa kemampuan manajemen secara langsung berpengaruh tidak signifikan terhadap kinerja usaha.

Hasil kajian ini mendukung teori dari Tidd dan Pavitt (1998) menyatakan bahwa kemampuan manajemen sangatlah penting dalam industri kecil, menengah dan 
industri besar, dimana masing- kemampuan manajemen yang masing memerlukan kegiatan meliputi perencanaan, manajemen untuk melakukan pengorganisasian, pengarahan, dan koordinasi dalam kemampuan atau pengawasan sebagai pembentuk skill yang dimiliki pekerja maupun koodinasi sumber-sumber yang dimiliki oleh perusahaan. Peran pimpinan atau pemilik perusahaan untuk memahami dan menjalankan fungsi-fungsi manajemen menjadi hal utama untuk mencapai keberhasilan suatu usaha. Manajemen adalah pencapaian tujuan organisasi dengan cara yang efektif dan efisien melalui perencanaan, pengorganisasian, pengarahan dan pengendalian sumber daya organisasi (Daft, 2006). KESIMPULAN

Kemampuan manajemen berpengaruh secara langsung terhadap kinerja IKM. Artinya kemampuan manajemen yang dimiliki oleh pemilik IKM sasirangan terbukti dapat meningkatkan kinerja IKM.. Hal ini menunjukkan bahwa pelaksanaan variable kemampuan manajemen dapat digunakan secara langsung untuk meningkatkan pertumbuhan penjualan, pertumbuhan keuntungan dan pertumbuhan modal sebagai pembentuk variable kinerja IKM. Dapat disimpulkan bahwa semakin tinggi kemampuan pemilik IKM sasirangan dalam menjalankan fungsi-fungsi manajemen yang meliputi memiliki kemampuan untuk membuat perencanaan strategi, membuat keputusan sendiri dengan baik tampa bantuan orang lain, mendistribusikan pekerjaan dengan baik kepada karyawan, membangun team kerja yang handal, berkomunikasi dengan baik terhadap karyawan, menyelesaikan pekerjaan tepat waktu, melakukan perubahan kearah pekerjaan yang lebih baik demi tercapainya tujuan 
perusahaan, mampu menyelesaikan konflik yang terjadi antara perusahaan dengan karyawan maupun dengan pelanggan maka akan semakin meningkatkan pertumbuhan penjualan, pertumbuhan keuntungan dan pertumbuhan modal. Kemampuan Manajemen berpengaruh signifikan bersifat positif terhadap Kinerja IKM. Temuan ini mendukung teori dan kajian empirik dari Tidd dan Pavitt (1998), ( Daft, 2006), Akgun et al. (2008), Man dan Wafa (2008), Suci ( 2009 ), Wai dan Kuan (2011), Chi et al (2011), Hsu (2012), Fening (2012), dan Dani et al. (2013).

\section{DAFTAR PUSTAKA}

Akgun, Ali E., Halit Keskin and John Byrne. 2008. "The Moderating Role of Environmental Dynamism Between Firm Emotional Capability and Performance", Journal of Organizational Change Management, Vol. 21, No. 2, Emerald Group Publishing Limited organizational capabilities or competencies, pp. 230-252.
Altinay, Levent and Wang, Catherine L. 2011. "The Influence of an Entrepreneur's Socio-cultural Characteristics on The Entrepreneurial Orientation of Small Firms", Journal of Small Business and Enterprise Development, Vol. 18, No. 4, Emerald Group Publishing Limited, pp. 673-694.

Anshoff, I. 1990. The New Corporate Strategy, McGraw-Hill, New York.

Chi, Kuang Hsin, Huery Ren Yeh, and Yu Ling Chen. 2011. "The Mediating Effect of Knowledge Management on Customer Orientation and Job Performance of Sales people".

Cresswell, John W., 2009, Reseach Design:

Qualitative, Quantitative and Mixed Methode Approaches. Third Edition, Sage Publication Inc., California.

Daft, Richard L., 2006, Management, Cenggage Learning Asia Pte, Singapore

Dani, Ibrahim, Idrus, M.S., Nimran, Umar, Sudiro, Achmad, 2013. “Business Strategy Role as Mediation of Management Capability and Orientation of Entrepreneurship on Business Performance (A Study on Micro and Small Scale Seaweed Business in 
Takalar District, South Sulawesi Province). Journal of Management Reseach ISSN 1941-899x, Vol.5, No.1

Dinas Perindustrian dan Perdagangan Provinsi Kalimantan Selatan, 2015, Daftar Sentra Industri Kerajinan Sasirangan Propinsi Kalimantan Selatan Tahun $2013-2014$

Edward, M. 1994, Non Govermental Organizations : Performance Hsu, Shu Hung, 2012. “Effects of Competitive Strategy, Knowledge Management and E-Business Adoption on Performance". The Journal of Human Resource and Adult Learning, Vol. 8, Num. 2.

Kaballu, O.U., dan Kameo, D.D. 2001. "Strategi Bertahan Usaha Kecil Dalam Menghadapi Krisis Ekonomi (Studi Industri Kecil Konveksi di Salatiga)", Dian Ekonomi, VII (2), September 2001: 191 - 205

Man, Mandy Mok Kim and Wafa Syed Azizi. 2008. "The Relationship Between Distinctive Capabilities, Innovativeness, Strategy Types and the Performance of Small and Medium: Size Enterprises (SMEs) on Malaysian Manufacturing Sector", The Journal of and Accountability-Beyond the Magic Bullet, Earthscan, London

Fening, Fred Appiah. 2012, “Impact of Quality Management Practices on the Performance and Growth of Small and Medium Sized Enterprises (Smes) in Ghana", International Journal of Business and Social Science Vol. 3 No. 13; July 2012.

American Academy of Business vol.13.

Peters, R.D., 1998. Entrepreneurship, Fourth Editon, McGraw Hill Companies, Inc, New York

Price, Robert W., 2004. Roadmap to Entrepreneurial Success:

Powerful.

Storey, D.J., 1994, Undestanding The Small Business Sector, London, Routledge. Strategies for Building a High-Profit Business, Publishing: AMACOM

Suci, Rahayu Puji, 2009, Peningkatan Kinerja melalui Orientasi Kewirausahaan, Kemampuan Manajemen, dan Strategi Bisnis, Jurnal Manajemen dan Kewirausahaan. Vol.11, No.1, Maret 2009, 4658 
Tidd, J., Bessant, J. and Pavitt, K., 1998, Managing InnovationIntegrating Technological, Market and Organizational Change, Hohn wiley and Sons, Chichester

Usric, Dusko and Mulej, Matjaz, 2005. "Theory and Practice of management Concepts: Slovania's Experiences. The Journal of Management Wai, Peng Wong and Kuan, Yew Wong, 2011. "Supply Chain Management, Knowledge Management Capability, and Their Linkages Towards Firm Performance", Business Process Management Journal, vol 17, Num 6, Emerald Group Publishing Limited, pp.910964.

Development; ABI/INFORM

Complete, pg. 856. 